\title{
Isolation and characterization of atriplex hortensis and sweet chenopodium quinoa starches
}

\author{
K. H. Wright \\ kamigo@gmail.com \\ K. C. Huber \\ Daniel J. Fairbanks \\ C. S. Huber
}

Follow this and additional works at: https://scholarsarchive.byu.edu/facpub

Part of the Food Science Commons, and the Nutrition Commons

\section{Original Publication Citation}

Wright KH, Huber KC, Fairbanks DJ and Huber CS. 22. Isolation and characterization of atriplex hortensis and sweet chenopodium quinoa starches. Cereal Chemistry 79(5): 715-719.

\section{BYU ScholarsArchive Citation}

Wright, K. H.; Huber, K. C.; Fairbanks, Daniel J.; and Huber, C. S., "Isolation and characterization of atriplex hortensis and sweet chenopodium quinoa starches" (2002). Faculty Publications. 529.

https://scholarsarchive.byu.edu/facpub/529 


\title{
Isolation and Characterization of Atriplex hortensis and Sweet Chenopodium quinoa Starches
}

\author{
K. H. Wright, ${ }^{1}$ K. C. Huber, ${ }^{2}$ D. J. Fairbanks, ${ }^{3}$ and C. S. Huber ${ }^{1,4}$
}

\section{ABSTRACT}

Cereal Chem. 79(5):715-719

\begin{abstract}
Starches from garden orach (Atriplex hortensis) and sweet quinoa (Chenopodium quinoa Willd. 'Surumi') seeds were isolated, examined for compositional characteristics, and compared with bitter quinoa (Chenopodium quinoa Willd.) starch. Garden orach and sweet quinoa seeds were similar in fat and ash contents, while garden orach seeds contained $\approx 10 \%$ more protein. Starches were isolated from seeds following a 12-hr soak in dilute alkaline solution using a series of grinding, screening, centrifugation, and washing steps. Isolated starches viewed by scanning electron microscopy yielded angular, polygonal granules $\approx 1-2 \mu \mathrm{m}$ in diameter. Starches
\end{abstract}

displayed typical A-type crystalline packing arrangements as determined by X-ray powder diffractometry. Apparent amylose contents for garden orach $(21.2 \%)$, sweet quinoa $(20.6 \%)$, and bitter quinoa (19.8\%) were determined according to colorimetric procedure. Differential scanning calorimetry data indicated a higher and wider gelatinization temperature range for garden orach as compared with sweet and bitter quinoa starches. Starch pasting profiles generated using a Rapid Visco Analyser indicated a reduced peak paste viscosity for garden orach starch relative to sweet and bitter quinoa and common corn starches.
Quinoa (Chenopodium quinoa) is a plant of the Chenopodiaceae family and a traditional food crop grown in the Andean region of South America. Once prized by the Incas as their "mother grain", today quinoa represents a valuable source of quality protein, carbohydrates, essential fatty acids, and micronutrients (Chauhan et al 1992; Koziol 1992; Wood et al 1993; Ahamed et al 1996; Qian and Kuhn 1999). Even with its exceptional nutritional value and functional starch, bitter saponins located in the pericarp of seeds limit quinoa as an acceptable and economical food source (Chauhan et al 1992). As alternatives to the saponin-containing quinoa (bitter quinoa), seeds from garden orach (Atriplex hortensis) and sweet quinoa (Chenopodium quinoa Willd. 'Surumi') may be considered.

Garden orach, also known as mountain spinach, sea purslane, or salt bush, appears to have had its origin in Europe and Siberia, and is considered to be one of the oldest cultivated plants, valued primarily for its leaves (Stevens 1994). While garden orach also has been used both as a potherb for traditional medicinal purposes and to control soil erosion, very little scientific information is available regarding the composition and properties of its seed constituents. In contrast to quinoa, garden orach is capable of growing under a wider range of environmental conditions and possesses approximately twice the amount of protein. Although sweet quinoa has been referenced previously (Koziol 1992), no work has been conducted to distinguish it from bitter quinoa with regard to starch composition and properties. The physicochemical and functional properties of bitter quinoa starch have been studied and reported (Atwell et al 1983; Lorenz 1990; Ruales and Nair 1994).

Because garden orach and sweet quinoa are considered potential alternative nutrient sources in developing countries for direct use in food applications or as functional ingredients, an understanding of their starch properties is needed. The objective of this study was to isolate and characterize starch from garden orach and sweet quinoa to provide information on their respective compositions, granule morphologies, and properties.

\footnotetext{
${ }^{1}$ Department of Food Science \& Nutrition, Brigham Young University, S221 ESC, Provo, UT 84602.

${ }^{2}$ Department of Food Science \& Toxicology, University of Idaho, Food Research Center, Moscow, ID 83844.

${ }^{3}$ Department of Botany and Range Science, Brigham Young University, PO Box 25245, Provo, UT 84602.

${ }^{4}$ Corresponding author. E-mail: clayton_huber@byu.edu. Fax: (801) 378-8714.
}

Publication no. C-2002-0806-01R.

(C) 2002 American Association of Cereal Chemists, Inc.

\section{MATERIALS AND METHODS}

Garden orach seeds were harvested from Brigham Young University research plots located in Spanish Fork, Utah and from native plants grown at Park City, Utah. Sweet and bitter quinoa seeds were obtained from Ezra Taft Benson Agriculture and Food Institute research plots located in Letanias, Bolivia. Sweet quinoa genotype was obtained through natural breeding and selection processes. Common corn starch was donated by the A.E. Staley Manufacturing Co. (Decatur, IL).

Garden orach and quinoa seeds were collected according to traditional methods, in which plant stems, containing seed clusters, were harvested by hand and allowed to dry in the sun for five days. Seed clusters were then placed in a tarp where friction was applied manually to thresh seeds. Threshed seeds were separated from the chaff by gathering up the threshed material from the tarp and allowing the seeds to fall back to the tarp (chaff was carried away by natural air currents). This procedure was repeated several times until all chaff was removed from the seeds.

\section{Compositional Analysis}

Proximate composition of whole seeds was determined by standard methods (AOAC 1995): total moisture (method 925.09), protein (method 967.06, Kjeldahl [N × 6.25]), fat (method 920.39, ether extraction by soxhlet), and ash (method 923.03). Total carbohydrate was determined by difference. Dietary fiber content of seeds was determined by AOAC method 991.43. Total starch content was assayed using Approved Method 76-13 (AACC 2000).

\section{Starch Isolation}

Starch was isolated from garden orach and quinoa seeds by a combination of procedures (Perez et al 1993; Qian and Kuhn 1999). Seeds $(100 \mathrm{~g})$ were soaked in $\mathrm{NaOH}(0.3 \%$, w/v) at a $1: 3$ parts ratio at ambient temperature for $12 \mathrm{hr}$, after which softened seeds were lightly ground with a mortar and pestle to release the starch material. The ground slurry was screened (50-mesh sieve) with further addition of $\mathrm{NaOH}$ solution to aid the passage of starch through sieve openings. Overs were subjected to additional grinding and screening steps until virtually all starch had been removed from the seeds. The sieved starch slurry was then ground in a Waring blender (1 min) followed by screening and washing with $\mathrm{NaOH}$ through a series of sieves (70, 100, 120, and 200 mesh). The collected filtrate was centrifuged $(2,000 \times g, 10 \mathrm{~min})$, after which the supernatant was discarded. The starch pellet was resuspended in alkaline solution, centrifuged (supernatant discarded), and scraped with a spatula to remove nonstarch material. This procedure (resuspension, centrifugation, scraping) was repeated three 
times. Isolated starch was then washed with four successive portions of deionized water $(1 \mathrm{~L})$, resuspended in deionized water $(1 \mathrm{~L})$, neutralized with $\mathrm{HCl}(1 M)$, and recovered by centrifugation. Purified starch was reslurried in ethanol, recovered on a Büchner funnel, and allowed to air dry.

\section{Starch Isolation}

Yield and nitrogen combustion values of isolated starches were determined. Starch yields were calculated from original seed sample weights and final extracted starch weights. Nitrogen combustion values were determined according to the crude protein combustion test using Approved Method 46-30 (AACC 2000).

\section{Granule Morphology}

Starch granule morphology was analyzed by scanning electron microscopy (SEM) (JEOL JSM-840A, Peabody, MA). Samples were mounted on specimen stubs using double-sided tape, sputtercoated with 8-10 A of gold-palladium, and viewed with an accelera- tion voltage of $15 \mathrm{kV}$. Images were captured using a digital acquisition system (ISI Systems, Santa Barbara, CA).

\section{Amylose Determination}

Apparent amylose contents were estimated for the isolated garden orach and quinoa starches according to the colorimetric assay reported by Morrison and Laignelet (1983). For determination of total amylose content, starch samples were defatted by ethanol extraction in a soxhlet apparatus $(24 \mathrm{hr})$, air-dried overnight to remove residual ethanol and oven-dried at $103^{\circ} \mathrm{C}$ for $1 \mathrm{hr}$. Defatted starch samples were analyzed using the apparent amylose procedure.

\section{Granule Crystallinity}

Powder X-ray diffraction (XRD) patterns of starches were obtained using an X-ray diffractometer (Siemens D5000, Bruker, Madison, WI). All starch samples were equilibrated in a moisture chamber to $12 \%$ before analysis. XRD data were collected using

TABLE I

Proximate Analysis, Fiber, and Starch Content of Garden Orach, Sweet, and Bitter Quinoa Seeds (g/100 g) ${ }^{\mathrm{a}}$

\begin{tabular}{|c|c|c|c|c|c|c|c|}
\hline Seed Type & Moisture & Protein & Fat & Ash & Total Carbohydrate & Total Dietary Fiber & Total Starch \\
\hline Garden orach & $9.1 \pm 0.06 \mathrm{a}$ & $25.7 \pm 0.71 \mathrm{a}$ & $6.2 \pm 0.43 a$ & $3.2 \pm 0.07 \mathrm{a}$ & $55.8 \pm 0.97 \mathrm{a}$ & $12.1 \pm 0.67 \mathrm{a}$ & $41.0 \pm 0.70 \mathrm{a}$ \\
\hline Sweet quinoa & $8.2 \pm 0.10 b$ & $14.8 \pm 0.18 b$ & $5.3 \pm 0.24 b$ & $2.6 \pm 0.04 b$ & $69.1 \pm 0.32 b$ & $8.8 \pm 0.26 b$ & $60.1 \pm 1.07 b$ \\
\hline Bitter quinoa & $9.0 \pm 0.07 \mathrm{a}$ & $15.7 \pm 0.06 \mathrm{~b}$ & $5.7 \pm 0.29 \mathrm{ab}$ & $3.1 \pm 0.05 \mathrm{a}$ & $66.5 \pm 0.25 c$ & $10.3 \pm 0.42 c$ & $53.5 \pm 1.10 c$ \\
\hline
\end{tabular}

a Average of three determinations \pm standard deviation. Means within a column sharing a common letter were not significantly different $(P \leq 0.05)$.
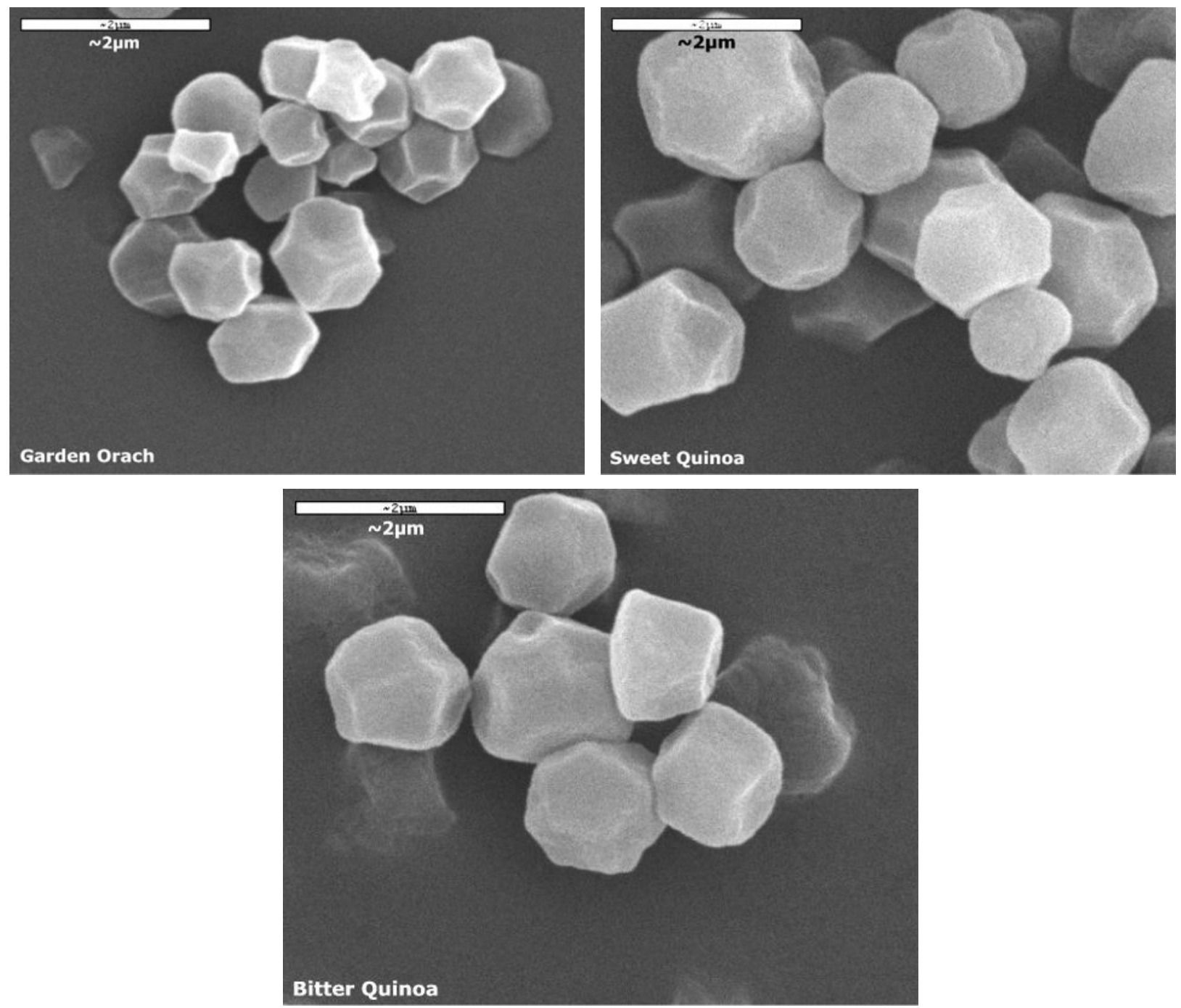

Fig. 1. Scanning electron micrographs of garden orach, sweet, and bitter quinoa starch granules. 
the parameters reported by Cheetham and Tao (1998) with modifications. Starch powder was packed tightly into rectangular aluminum cells and exposed to the X-ray beam with the X-ray generator running at $40 \mathrm{kV}$ and $30 \mathrm{~mA}$. The scanning regions of the diffraction angle $2 \theta$ were $4-30^{\circ}$ with step intervals of 0.03 , scan rate $2^{\circ} / \mathrm{min}$, Sollet and divergence slit $1^{\circ}$, receiving slit $1^{\circ}$, and scattering slit $0.15^{\circ}$.

Starch granule crystallinity was calculated according to the procedure reported by Nara and Komiya (1983). The crystalline region (area 1) was estimated as the sum of the tail-to-tail areas under principal peaks of the X-ray diffractogram, while the amorphous region (area 2) was estimated as the area between the tail-to-tail baseline of the principal peaks and an imaginary line connecting the first and last data points of the diffractogram. Granule crystallinity was calculated as the percentage of area 1 to the total area (area 1 + area 2).

\section{Starch Gelatinization}

Gelatinization properties of the isolated starches were analyzed by differential scanning calorimetry (DSC) (Pyris-1 thermal analytical system, Perkin-Elmer, Norwalk, CT). Starch samples $(8.0 \pm 0.1$ $\mathrm{mg}, \mathrm{db}$ ) were weighed directly into stainless steel sample pans, mixed with deionized water $(30 \mu \mathrm{L})$ to form starch slurries, and sealed. Samples were allowed to equilibrate overnight and then heated from 20 to $120^{\circ} \mathrm{C}$ at $10^{\circ} \mathrm{C} / \mathrm{min}$. A pan containing a $1: 2$ ratio of $\mathrm{Al}_{2} \mathrm{O}_{3}$ to water was used as a reference. Enthalpy change $(\Lambda H)$, gelatinization onset temperature $\left(T_{\mathrm{o}}\right)$, peak temperature $\left(T_{\mathrm{p}}\right)$, completion temperature $\left(T_{\mathrm{c}}\right)$, and gelatinization ranges were computed automatically.

\section{Starch Pasting Properties}

A Rapid Visco Analyser (RVA) (Newport Scientific, Sydney, Australia) was used to analyze pasting properties of the isolated starches. Starch suspensions were prepared by weighing starch (3.0 g, 14\% moisture basis) into tarred aluminum canisters to which deionized water $(\approx 25 \mathrm{~mL})$ was added to yield a total material weight of $28 \mathrm{~g}$. The resulting slurry was stirred for several seconds using a Teflon-coated spatula to disperse the starch and break apart lumps. Starches were analyzed according to the RVA Standard 1 profile: initial temperature of $50^{\circ} \mathrm{C}(1 \mathrm{~min})$, linear heating to

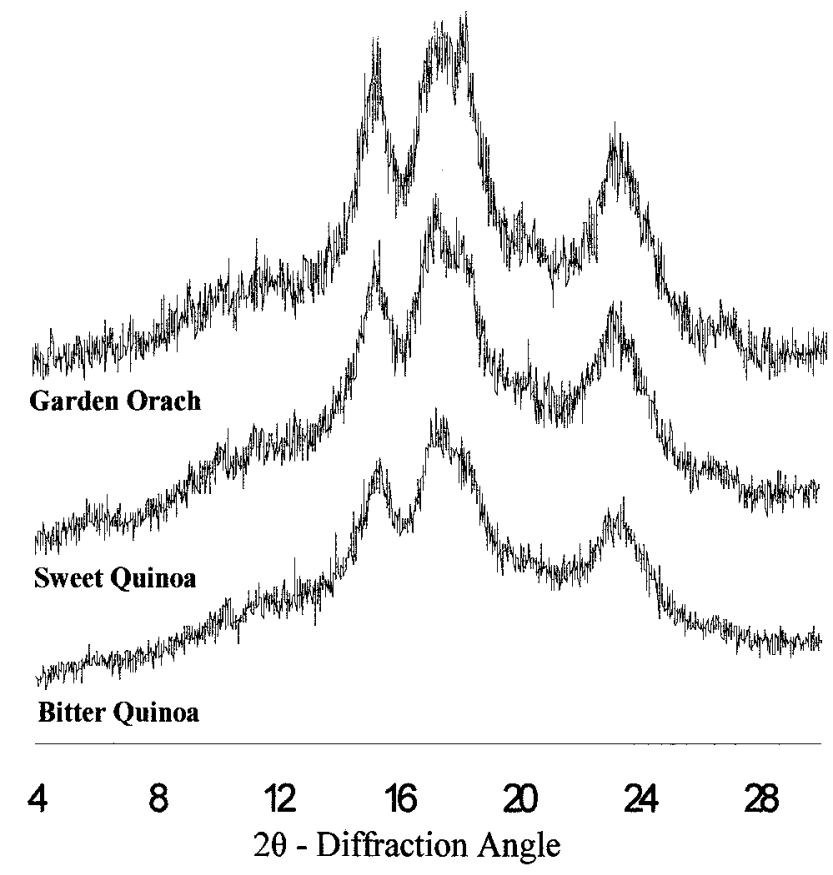

Fig. 2. X-ray powder diffraction spectra for garden orach, sweet, and bitter quinoa starches. $95^{\circ} \mathrm{C}$ (3.7 min), holding period at $95^{\circ} \mathrm{C}(2.5 \mathrm{~min})$, linear cooling to $50^{\circ} \mathrm{C}(3.8 \mathrm{~min})$, and final hold at $50^{\circ} \mathrm{C}(2 \mathrm{~min})$ to yield a total run time of $13 \mathrm{~min}$. Starch suspensions were stirred at an initial rate of $960 \mathrm{rpm}(15 \mathrm{sec})$ followed by a constant stirring rate of 160 $\mathrm{rpm}$ for the remainder of the run.

\section{Statistical Analysis}

Starch samples in the study were generated through three separate isolations (100-g seed batches) that were pooled before analysis. All analyses were conducted in triplicate unless otherwise stated. Starch nitrogen and pasting determinations were performed in duplicate. All data was subjected to analysis of variance using the general linear model (GLM) procedure, and means were separated by Duncan's multiple range test with SAS software (v. 8.1, SAS Institute, Cary, NC).

\section{RESULTS AND DISCUSSION}

The proximate compositions of garden orach, sweet, and bitter quinoa seeds used for starch isolation are provided in Table I. Proximate composition values for bitter quinoa are in good agreement with data reported earlier by Galwey et al (1990) and Koziol (1992). Minimal compositional differences were observed between sweet and bitter quinoa samples. Sweet quinoa showed slightly lower values for fat, ash, and total dietary fiber and somewhat greater amounts of carbohydrate and starch in contrast to bitter quinoa. In comparison to both sweet and bitter quinoa, garden orach seeds possessed similar values for fat and ash contents, but exhibited substantially higher protein and lesser carbohydrate contents.

The percent yields and nitrogen contents of the isolated starches are listed in Table II. Starch yields obtained for bitter quinoa were higher than those previously reported in literature (Mundigler 1998). While sweet quinoa seeds appeared to possess a slightly higher starch content than those of bitter quinoa (Table I), a greater starch yield was obtained for bitter quinoa (almost $100 \%$ starch recovery). Garden orach, with the lowest starch yield ( $\approx 66 \%$ of total starch recovered from seeds), still provided an acceptable recovery. It is anticipated that starch yields for sweet quinoa and garden orach could yet be improved with additional research. With acceptable yields and reasonably low nitrogen values, it was concluded that the isolation procedures used were sufficient in obtaining representative and pure starch samples.

SEM observation of isolated starch from garden orach, sweet, and bitter quinoa revealed angular, polygonal granules $\approx 1$ to $2 \mu \mathrm{m}$

TABLE II

Starch Yield ${ }^{\mathrm{a}}$ and Nitrogen Content for Garden Orach, Sweet, and Bitter Quinoa

\begin{tabular}{lcc}
\hline Starch Type & Starch Yield $(\boldsymbol{\%})$ & Nitrogen Content $(\boldsymbol{\%})$ \\
\hline Garden orach & 26.9 & 0.06 \\
Sweet quinoa & 45.3 & 0.05 \\
Bitter quinoa & 53.3 & 0.08 \\
\hline
\end{tabular}

a Starch g/100 g of seed.

TABLE III

Apparent and Total Amylose Content of Garden Orach, Sweet, and Bitter Quinoa Starches ${ }^{\mathrm{a}}$

\begin{tabular}{lcc}
\hline & \multicolumn{2}{c}{ \% Amylose $^{\mathrm{b}}$} \\
\cline { 2 - 3 } Starch Type & Apparent & Total \\
\hline Garden orach & $21.2 \pm 0.36 \mathrm{a}$ & $20.6 \pm 0.33 \mathrm{a}$ \\
Sweet quinoa & $20.6 \pm 0.23 \mathrm{~b}$ & $21.0 \pm 0.51 \mathrm{a}$ \\
Bitter quinoa & $19.8 \pm 0.32 \mathrm{c}$ & $20.6 \pm 0.73 \mathrm{a}$ \\
\hline
\end{tabular}

${ }^{a}$ Average of three determinations \pm standard deviation. Means within a column sharing a common letter were not significantly different $(P \leq 0.05)$.

${ }^{\mathrm{b}}$ No significant difference between apparent and total \% amylose values for each starch type. 
TABLE IV

Crystallinity of Garden Orach, Sweet, and Bitter Quinoa Starches

\begin{tabular}{lc}
\hline Starch Type & \% Crystallinity \\
\hline Garden orach & $47.7 \pm 0.58 \mathrm{a}$ \\
Sweet quinoa & $38.0 \pm 2.00 \mathrm{~b}$ \\
Bitter quinoa & $36.7 \pm 1.53 \mathrm{~b}$ \\
\hline a Average of three determinations \pm standard deviation. Means within a \\
column sharing a common letter were not significantly different $(P \leq 0.05)$
\end{tabular}

in diameter (Fig. 1). Starch granules from garden orach and sweet quinoa were similar in shape to those of bitter quinoa. However, garden orach starch granules appeared to be somewhat smaller and more angular than those of sweet and bitter quinoa. Starch granules from garden orach, sweet, and bitter quinoa are all smaller than those found in common corn starch, and are comparable in size to other small granule starches such as amaranth. Granule surfaces of isolated starches appeared smooth and intact, displaying no visible porosity under microscopic observation.

Apparent and total percent amylose values of the isolated starches are shown in Table III. No significant differences were observed between the apparent and total amylose starch contents for any of the analyzed starches. This result would imply that garden orach, sweet, and bitter quinoa contain very little lipid associated with their isolated starches. Total amylose values did not differ significantly among garden orach, sweet, and bitter quinoa starches, while only subtle differences in apparent amylose values were observed among the three starches. The apparent amylose value reported here for bitter quinoa (19.8\%) was higher than previously reported (9-12\%) by Lorenz (1990) and Qian and Kuhn (1999), yet a range of amylose values appears to be common in most grains. Isolation methods, cultivar, maturity, or growing conditions may have influenced the higher amylose values reported here.

Garden orach and sweet quinoa starches exhibited the A-type XRD crystalline arrangement pattern that is associated with bitter quinoa and typical of cereal starches (Fig. 2). Estimated X-ray crystallinities for bitter and sweet quinoa starches were 36.7 and $38.0 \%$, respectively, compared with the $47.7 \%$ crystallinity for garden orach (Table IV). Crystallinity values for quinoa starches reported here are in good agreement with values reported by Qian and Kuhn (1999).

Gelatinization properties of starches measured by DSC are summarized in Table V. Transition temperatures $\left(T_{\mathrm{o}}, T_{\mathrm{p}}, T_{\mathrm{c}}\right)$ and enthalpy $(\Delta H)$ for sweet quinoa were very similar to those of bitter quinoa. Garden orach had higher onset, peak, and completion gelatinization temperatures, but exhibited enthalpy values similar to those of sweet and bitter quinoa starches. These relatively low gelatinization temperature ranges might suggest the presence of short branch chains for the amylopectin of garden orach and quinoa starches (Jane et al 1999). Gelatinization occurred over a wider temperature range for garden orach starch $\left(15.4^{\circ} \mathrm{C}\right)$ compared with both sweet $\left(12.7^{\circ} \mathrm{C}\right)$ and bitter quinoa $\left(12.9^{\circ} \mathrm{C}\right)$ starches. The wider gelatinization temperature range and higher onset gelatinization temperature for garden orach coincided with its higher degree of crystallinity determined by XRD. Observed differences between the gelatinization behaviors of garden orach and the quinoa starches might also be attributable to the amylopectin fine structure. (Information will be presented in a subsequent work.) No obvious peaks for melting of amylose-lipid complexes were observed for any of the starches. These findings were consistent with the lack of difference observed between the apparent and total amylose values obtained for the three starches.

The pasting viscosity profiles for garden orach and sweet quinoa are compared with bitter quinoa and corn starch in Fig. 3. Viscosity data are summarized in Table VI. Pasting curves revealed that garden orach, sweet, and bitter quinoa starches followed the typical pasting curve pattern for cereal starches. The RVA curve

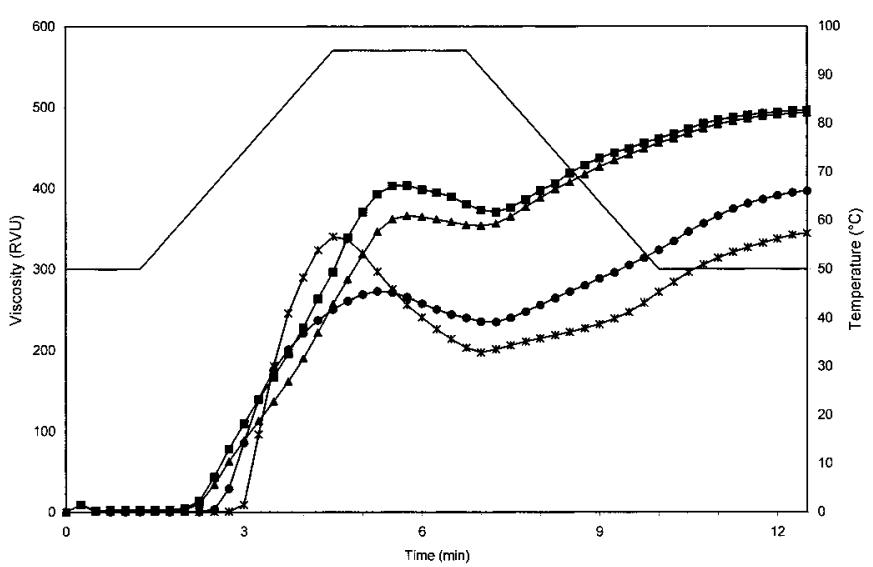

Fig. 3. Pasting profiles of garden orach $(\mathbf{O})$, sweet quinoa $(\mathbf{A})$, bitter quinoa ( $\mathbf{\square})$, and corn (X) starches measured by Rapid Visco Analyser.

obtained for bitter quinoa was very similar to results reported by Wilhelm et al (1998) and Qian and Kuhn (1999). The results showed that the RVA pasting temperatures (temperature at which a measurable viscosity increase was detected upon gelatinization) for all starch samples occurred in the same order as for DSC onset gelatinization temperatures. Both sweet and bitter quinoa starches exhibited higher peak paste viscosities as compared with garden orach and common corn starches. For garden orach starch, the low peak paste viscosity value might be a function of its high degree of crystallinity or its somewhat wider DSC gelatinization temperature range. Thus, all granules may not reach a maximally swollen state at the same time within the RVA. In particular, both quinoa starches possessed low breakdown values (relative to common corn starch), in addition to high values for paste peak viscosity, which would imply reasonable stability to heat and shear. Bitter and sweet quinoa starches and garden orach starch all exhibited comparable setback values and higher final viscosities when compared with common corn starch.

\section{CONCLUSIONS}

Isolated starches from garden orach (Atriplex hortensis) and sweet quinoa (Chenopodium quinoa Willd. 'Surumi') consisted of small (1-2 $\mu \mathrm{m}$ diameter), angular-shaped granules similar to those of bitter quinoa (although garden orach granules were slightly smaller and more angular). Overall, sweet quinoa starch possessed very similar properties as compared with bitter quinoa starch. Garden orach and quinoa starches possessed comparable total amylose contents, although the amylose value reported here for bitter quinoa was somewhat higher than previously reported values. This finding could imply that there is some genetic diversity with respect to quinoa starch composition, but this will warrant further investigation. While all three starches exhibited A-type crystalline arrangement patterns, garden orach starch granules possessed the highest degree of crystallinity, which translated into lower RVA peak, trough, and final viscosities for garden orach starch relative to both quinoa starches. All three starches possessed favorable hot paste stability (low RVA breakdown values) and formed strong gels (high final viscosity values) relative to the common corn starch reference. The low lipid content of garden orach and both quinoa starches could prove beneficial for applications requiring translucent gels, while the small granule size of the three starches provides a favorable surface area for potential use in coatings or films. Thus, the overall attributes and properties of garden orach and quinoa starches may prove valuable in meeting the needs of an expanding and increasingly diversified food industry. The absence of saponins in both garden orach and sweet quinoa seeds also makes them attractive alternatives to bitter quinoa, particularly in whole seed applications. 
TABLE V

Thermal Properties of Starch Gelatinization Determined by Differential Scanning Calorimetry ${ }^{\mathrm{a}}$

\begin{tabular}{lccccc}
\hline Starch Type & $\boldsymbol{T}_{\mathbf{0}}\left({ }^{\mathbf{}} \mathbf{C}\right)$ & $\boldsymbol{T}_{\mathbf{p}}\left({ }^{\mathbf{}} \mathbf{C}\right)$ & $\boldsymbol{T}_{\mathbf{c}}\left({ }^{\circ} \mathbf{C}\right)$ & Range $\left({ }^{\circ} \mathbf{C}\right)$ & $\boldsymbol{\Delta} \boldsymbol{H}(\mathbf{J} / \mathbf{g})$ \\
\hline Garden Orach & $59.0 \pm 0.31 \mathrm{a}$ & $64.9 \pm 0.30 \mathrm{a}$ & $74.4 \pm 0.63 \mathrm{a}$ & $15.4 \pm 0.94 \mathrm{a}$ & $12.1 \pm 0.27 \mathrm{a}$ \\
Sweet Quinoa & $51.8 \pm 0.07 \mathrm{~b}$ & $56.1 \pm 0.50 \mathrm{~b}$ & $64.5 \pm 0.15 \mathrm{~b}$ & $12.7 \pm 0.19 \mathrm{~b}$ & $12.6 \pm 1.07 \mathrm{a}$ \\
Bitter Quinoa & $51.4 \pm 0.14 \mathrm{~b}$ & $55.7 \pm 0.16 \mathrm{~b}$ & $64.3 \pm 0.03 \mathrm{~b}$ & $12.9 \pm 0.16 \mathrm{~b}$ & $12.6 \pm 0.43 \mathrm{a}$ \\
\hline
\end{tabular}

${ }^{a}$ Average of three determinations \pm standard deviation. Means within a column sharing a common letter were not significantly different $(P \leq 0.05)$. Onset temperature $\left(T_{\mathrm{o}}\right)$, peak temperature $\left(T_{\mathrm{p}}\right)$, completion temperature $\left(T_{\mathrm{c}}\right)$, and enthalpy change $(\mathrm{NH})$ of starch gelatinization; range of gelatinization $T_{\mathrm{c}}-T_{\mathrm{o}}$.

TABLE VI

Pasting Properties of Garden Orach, Sweet Quinoa, Bitter Quinoa, and Corn Starches Measured by Rapid ViscoAnalyzer

\begin{tabular}{|c|c|c|c|c|c|c|}
\hline \multirow[b]{2}{*}{ Starch Type } & \multirow[b]{2}{*}{ Pasting Temp. $\left({ }^{\circ} \mathrm{C}\right)$} & \multicolumn{5}{|c|}{ Viscosity $(\text { RVU) })^{a}$} \\
\hline & & Peak & Hold & Breakdown & Final & Setback \\
\hline Garden Orach & $70.4 \pm 0.00 \mathrm{a}$ & $273.8 \pm 1.71 \mathrm{a}$ & $237.5 \pm 3.83 a$ & $36.3 \pm 2.12 \mathrm{a}$ & $397.2 \pm 0.35 a$ & $123.4 \pm 1.35 a$ \\
\hline Sweet Quinoa & $65.3 \pm 0.04 b$ & $367.3 \pm 2.12 b$ & $357.9 \pm 6.42 b$ & $9.4 \pm 4.30 b$ & $495.9 \pm 3.71 b$ & $138.0 \pm 2.72 b$ \\
\hline Bitter Quinoa & $63.5 \pm 0.07 c$ & $402.5 \pm 2.06 c$ & $369.4 \pm 1.83 b$ & $33.1 \pm 0.23 \mathrm{a}$ & $495.1 \pm 2.30 b$ & $125.8 \pm 0.47 a$ \\
\hline Corn $^{\mathrm{b}}$ & 75.5 & 339.9 & 197.4 & 142.5 & 344.3 & 146.8 \\
\hline
\end{tabular}

${ }^{a}$ Measured in Rapid Visco Analyser units. Average of two determinations \pm standard deviation. Means within a column sharing a common letter were not significantly different $(P \leq 0.05)$

b Single observation collected to use as a reference.

\section{LITERATURE CITED}

Ahamed, N. T., Singhal, R. S., Kulkarni, P. R., and Pal, M. 1996. Physicochemical and functional properties of Chenopodium quinoa starch. Carbohydr. Polym. 31:99-103.

American Association of Cereal Chemists. 2000. Approved Methods of the AACC, 10th ed. Methods 46-30 and 76-13. The Association: St. Paul, MN.

AOAC. 1995. Official Methods of Analysis of the Association of Official Analytical Chemists, 16th ed. Methods 920.39, 923.03, 925.09, 967.06, and 991.43. The Association: Arlington, VA.

Atwell, W. A., Patrick, B. M., Johnson, L. A., and Glass, R. W. 1983. Characterization of quinoa starch. Cereal Chem. 60:9-11.

Chauhan, G. S., Eskin, N. A. M., and Tkachuk, R. 1992. Nutrients and antinutrients in quinoa seed. Cereal Chem. 69:85-88.

Cheetham, N. W. H., and Tao, L. 1998. Variation in crystalline type with amylose content in maize starch granules: An X-ray powder diffraction study. Carbohydr. Polym. 36:277-284.

Galwey, N. W., Leakey, C. L. A., Price, K. R., and Fenwick, G. R. 1990. Chemical composition and nutritional characteristics of quinoa (Chenopodium quinoa Willd.). Food Sci. Nutri. 42F:245-261.

Jane, J., Chen, Y. Y., Lee, L. F., McPherson, A. E., Wong, K. S., Radosavljevic, M., and Kasemsuwan, T. 1999. Effect of amylopectin branch chain length and amylose content on the gelatinization and pasting properties of starch. Cereal Chem. 76:629-637.

Koziol, M. J. 1992. Chemical composition and nutritional evaluation of quinoa (Chenopodium quinoa Willd.). J. Food Comp. Analysis 5:35-68.

Lorenz, K. 1990. Quinoa (Chenopodium quinoa) starch—Physicochemical properties and functional characteristics. Starch 42:81-86.

Morrison, W. R., and Laignelet, B. 1983. An improved colorimetric procedure for determining apparent and total amylose in cereal and other starches. J. Cereal Sci. 1:9-20.

Mundigler, N. 1998. Isolation and determination of starch from amaranth (Amaranthus cruentus) and quinoa (Chenopodium quinoa). Starch 50:67-69.

Nara, S., and Komiya, T. 1983. Studies on the relationship between water-saturated state and crystallinity by the diffraction method for moistened potato starch. Starch 35:407-410.

Perez, E., Bahnassey, Y. A., and Breene, W. M. 1993. A simple laboratory scale method for isolation of amaranth starch. Starch 45:211-214.

Qian, J. Y., and Kuhn, M. 1999. Characterization of Amaranthus cruentus and Chenopodium quinoa starch. Starch 51:116-120.

Ruales, J., and Nair, B. M. 1994. Properties of starch and dietary fiber in raw and processed quinoa (Chenopodium quinoa, Willd.) seeds. Plant Foods Human Nutr. 45:223-246.

Stevens, J. M. 1994. Orach-Atriplex hortensis L. Fact sheet HS-637, Horticultural Sciences Department, Florida Cooperative Extension Service, Inst. Food and Agricultural Sciences. University of Florida: Gainesville.

Wood, S. G., Lawson, L. D., Fairbanks, D. J., Robinson, L. R., and Anderson, W. R. 1993. Seed lipid content and fatty acid composition of three quinoa cultivars. J. Food Comp. Analysis 6:41-44.

Wilhelm, E., Themeier, H. W., and Lindhauer, M. G. 1998. Feinkornstärken und hydrophile polymere als komponenten fur neue biologisch abbaubare zweiphasenwerkstoffe für spezielle anwendungen teil 1: Separations - und aufbereitungstechniken für feinkornstärken von quinoa und amaranth. Starch 50:7-13.

[Received July 30, 2001. Accepted April 10, 2002.] 